\title{
Circumcision weeks: making circumcision part of routine training and service delivery at district-level hospitals in South Africa
}

\author{
Peters F, MBChB, MFamMed \\ Senior Family Physician, Pretoria West Hospital, Department of Family Medicine, University of Pretoria \\ Marcus TS, PhD \\ Extraordinary Professor, Department of Family Medicine, University of Pretoria \\ Correspondence to: Frank Peters, e-mail: frank.peters@up.ac.za \\ Keywords: safe male circumcision, minor surgery competency, training, district health services
}

\begin{abstract}
Background: Medically safe, elective male circumcision supports traditional and cultural rites of passage by reducing the risk of adverse events and death among men undergoing initiation. It is a way of preventing penile conditions that arise from being uncircumcised. It also protects against various sexually transmitted infections, playing a particularly important role in human immunodeficiency virus (HIV) prevention, as it protects against HIV infection in men by up to $60 \%$. It also helps reduce herpes simplex virus type 2, a key biological co-factor thought to account for some human susceptibility to HIV infection and human papillomavirus. To address these needs and to meet the World Health Organization's call to upscale male circumcision to $80 \%$ in HIV/AIDS epidemic-gripped sub-Saharan Africa, there is a need to provide male circumcision as standard care in district health.
\end{abstract}

Method: A retrospective review of three years of circumcision services, using the sleeve method, and not the high-volume, forceps-guided method, and training at a Level 1 district hospital in South Africa.

Results: Two hundred and twenty-one medical circumcisions were performed, increasing significantly in each successive year. Mostly, they were carried out under local anaesthetic, and there were only four complications, all of which were successfully resolved. The average age of the patients was 20 , and generally, they elected to have medical circumcision carried out for cultural reasons. Some 60 students and clinicians were trained in safe medical male circumcision.

Conclusion: To meet the growing demand for male medical circumcision, especially among teenagers and young adult men at district-level hospitals, there is a need to significantly expand the surgical competency of clinicians in this field. "Circumcision weeks" are one way of routinely upscaling surgical skill levels, while simultaneously responding to increased patient demand for safe medical circumcision.

(P) Peer reviewed. (Submitted: 2010-07-26, Accepted: 2010-10-27). ๑ SAFP

S Afr Fam Pract 2011;53(3):262-266

\section{Introduction}

Three interrelated issues coincide to make male circumcision a critical service that needs to be provided as standard care in district health centres in South Africa. One relates to the fact that male circumcision is a long-established social and cultural practice in South Africa, with both traditional and medical antecedents. It is a rite of passage for boys into manhood among the African majority, albeit to varying degrees. Circumcision is common practice among Xhosa, Venda and Sepedi speakers, but only variously practised among Sotho, Ndebele, Shangaan and Zulu speakers. Among the former, the tradition requires full circumcision. Among the latter, the tradition is often one of partial circumcision.
It is a birth rite of Jewish and Muslim South African children, and it was the standard of available medical care to male babies born in government hospitals up until the last few decades of the $20^{\text {th }}$ century. Although circumcision is an established medical and traditional practice historically, for more than two decades, there has been an attrition of appropriate healthcare skills and management among both traditional and medical practitioners.

In societies in which circumcision is the care standard, surgical complications should be infrequent, whether they are performed medically or ritually. In Israel, for example, where neonatal circumcision is the care standard, complications are rare, and are mostly mild and correctable. Most importantly, the quality of service is comparable in that there are no significant differences 
in the type of complications arising from either medical or ritual circumcision. ${ }^{1}$ This is not the case in South Africa. While there is a repository of surgical skills in some ritual circumcision communities, and among increasingly fewer junior doctors and general practitioners in medical settings, ${ }^{2}$ there are persistent circumcision complications and fatalities among important segments of society, especially where ritual or traditional adult circumcision is practised. The skill and healthcare management gap among traditional "surgeons" is strongly evident in the Eastern Cape, for example, where hospital admissions, amputations and deaths are routine during the annual circumcision seasons. In the period 2001-2006, Meissner and Buso ${ }^{3}$ found that the high rate of complications remained virtually unchanged, despite legislation ${ }^{4}$ or training efforts to impart skills to traditional practitioners and nurses. ${ }^{5}$ Peltzer et al found high rates of complications $(20.8 \%$ mild delayed wound healing, $16.2 \%$ mild wound infection, $10.5 \%$ mild pain, $10.4 \%$ insufficient skin removed) among initiates from schools where traditional surgeons and nurses had been trained. ${ }^{5}$ By contrast, in a study by Peltzer and Kanta, it was found that complications in clinical settings were much lower. ${ }^{6}$ This study found seven $(9 \%)$ adverse events were noted. Therefore, there is a need to establish male circumcision as a medically safe standard procedure for men to prevent unnecessary illness and death.

The second issue relates to the role of circumcision in health promotion and the prevention of sexually transmitted infections (STIs). The idea that male circumcision may be protective against human immunodeficiency virus (HIV) dates back to the late 1980s, when several studies suggested that male circumcision might account for the marked difference in HIV prevalence in West Africa and East/Southern Africa. ${ }^{7}$ Between 2002-2006, three randomised controlled trials were conducted on men from the general population in South Africa $(n=3274)$, Uganda $(n=4996)$, and Kenya $(n=2784)$. In a systematic review of these trials, Siegfried et al, ${ }^{8}$ concluded that "there is strong evidence that medical male circumcision reduces the acquisition of HIV by heterosexual men by between $38-66 \%$ over 24 months".

The primary reason that circumcision prevents HIV infection in men is because it removes the prepuce (or foreskin). Biologically, the inner foreskin, which is removed $5 \mathrm{~mm}$ from the glans with the sleeve method, is much less keratinised than other genital mucosa, so its numerous Langerhans cells and other immune cell targets are unusually susceptible to HIV infection. In vitro viral uptake in this tissue has been found to be seven times more efficient than that in cervical tissue. The highly vascular prepuce also allows access to the virus, as it is subject to micro-lesions during sexual intercourse. A partially removed prepuce is not deemed to be protective of micro-lesions.
Male circumcision, on its own, does not directly protect women against HIV infection at an individual level. However, the containment of the epidemic in West Africa and modelling (e.g. Alsallaq et al) ${ }^{9}$ suggests that longer term benefits to women can be anticipated at a population level, as the pool of HIV infection in the male population reduces with time.

There are other known disease-prevention benefits for both men and their female partners resulting from male circumcision. ${ }^{10}$ Its contribution to reducing the incidence of herpes simplex virus type 2 (HSV-2), a key biological cofactor thought to account for some human susceptibility to HIV infection and human papillomavirus (HPV), is especially important. ${ }^{11}$ This means that it also protects women against cervical cancer. ${ }^{12,13}$ Circumcision protects both men and women against ulcerative STIs too. Two circumcision trials have reported halving of the risk of genital ulcer disease. ${ }^{14,15}$

Neonatal circumcision is positively associated with a reduced risk of acquiring penile cancer ${ }^{16}$ because it contributes to a reduced presence of HPV in adult men. Similarly, the incidence of prostate cancer is 1.6-2-fold greater in uncircumcised men. ${ }^{17}$ There appears to be an inverse relationship between prostate cancer and male


inflammation and infection of the skin of the penis.

Incomplete circumcision, due to poor surgical skills, ${ }^{5}$ partial circumcision practices such as ukugweda among Zuluspeaking communities, "where the foreskin is not removed, but an elastic band of tissue under the penis glans is cut", ${ }^{19}$ or the varying practices among Sotho-speaking communities described by Letsie ${ }^{20}$ are unlikely to have the same protective effects against HIV and other STIs. Therefore, there is a need to ensure that male circumcision properly protects against HIV, STIs and other diseases.

The evident individual and public health benefits of safe male circumcision in the context of a generalised HIV/AIDS epidemic and widespread, high-risk traditional circumcision practices both point to the need to make safe, infectionprotective and affordable circumcision widely available at the primary healthcare level in South Africa.

This gives rise to the third issue, namely whether it is possible to upscale male circumcision to reach $80 \%$ of young men within the next five years, as has been called for by the World Health Organization. ${ }^{21}$ While planning to introduce widespread male circumcision services is underway, voluntary, safe and effective male circumcision at district health level already exists.

The aims of this study were to describe three years of circumcision services being provided at a Level 1 district hospital, and to propose a training-based approach to 
service expansion that will make delivery viable at districtlevel hospitals, community health centres and private practices across the country.

\section{Method}

This article reports on a retrospective review of all circumcisions and penile surgeries undertaken by an experienced family physician over the three-year period February 2007-February 2010 at a Level 1 district hospital in the Gauteng province, South Africa. The patients were all boys or men who voluntarily presented themselves at a Level 1 hospital seeking to be medically circumcised or treated. Patients or patients and their guardians were informed about procedures and risks, and gave informed consent for the operation. They were admitted to a day ward before undergoing surgery. The surgery was performed either under general or local anaesthetic, using the penile ring block technique. The coronal glans-level resection method of circumcision was used as an established safe and acceptable procedure. Post-surgery, all patients were given health education regarding wound care and prevention of infection, including HIV and STIs. In particular, they were advised to abstain from masturbation and all forms of sex for six weeks after the operation, and to use a condom every time once they resumed sexual activity. A total of 252 penile surgeries were undertaken in the three-year period. Thirtytwo non-circumcision surgical procedures took place, most of which related to phimosis in young boys. The study was approved by the University of Pretoria's Faculty of Health Sciences main ethics committee.

\section{Results}

In the three-year period under review, 220 circumcisions were performed by, or under, the supervision of the family physician. Twenty-nine (13\%) operations were carried out under general anaesthetic, because patients either preferred not to be awake during the procedure, or because their age or level of anxiety made it a more advisable choice. The rest of the operations $(n=191)$ were carried out under local anaesthetic.

As Figure 1 shows, every year, the level of interest in elective surgery grew steadily.

An additional 31 circumcisions were performed by February 2010 , the end of the review period. Five of the patients were white, the remainder $(97,5 \%)$ were black (African, coloured or Indian) boys or men. They ranged in age from 7-75 years, with an average age of 20 and a modal age 16 years. Culture was the predominant reason that patients or their parents gave for electing to have circumcision surgery (77\%). They wanted to adhere to their cultural tradition of male

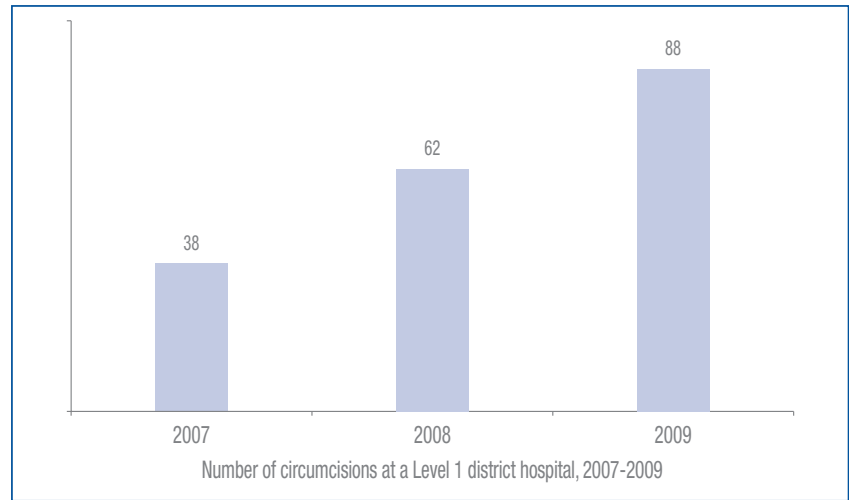

Figure 1: Number of circumcisions at a Level 1 district hospital, 2007-2009

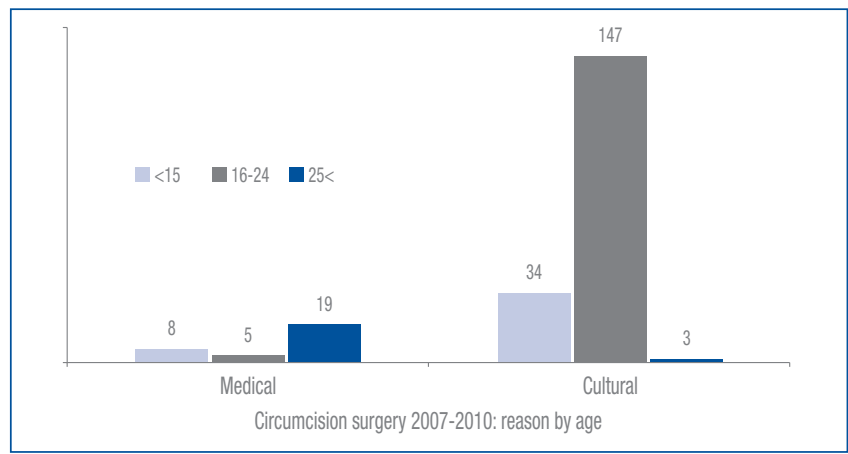

Figure 2: Circumcision surgery 2007-2010: reason by age

circumcision as a rite of passage, albeit under medically safe conditions. The remainder (13\%) required circumcision for medical reasons, and in particular for condylomata, phimosis or paraphimosis.

An analysis of patients' reasons for circumcision according to their age clearly revealed the importance and acceptability of offering safe medical circumcision at district level in support of cultural traditions (see Figure 2).

\section{Complications}

Four complications (1.8\%) arose from the circumcision and related penile surgeries in the three-year period under review. In 2009, a patient had to have the circumcision redone. In 2010, there were two postoperative haemorrhages that required surgical intervention. These complications arose within two hours and three days respectively. In the threeyear period there was one case of local sepsis, which was treated with antibiotics and which led to full recovery within 24 hours.

\section{Training}

Minor surgery, including circumcision, needs to become an essential part of district-level health and the skill repertoire of medical practitioners. General practitioners and family physicians, especially, need to acquire or maintain this skill. In the three-year review period, as 
Table I: Circumcision and related surgery training (2007-2010)

\begin{tabular}{|c|c|c|c|c|c|}
\hline \multicolumn{3}{|c|}{ Trainee } & \multicolumn{3}{|c|}{$\begin{array}{l}\text { Training opportunities under } \\
\text { general and local anaesthetic }\end{array}$} \\
\hline Year & No & Type & $\begin{array}{l}\text { Observed } \\
\text { operation }\end{array}$ & $\begin{array}{c}\text { Assisted in } \\
\text { operation }\end{array}$ & $\begin{array}{l}\text { Performed } \\
\text { operation }\end{array}$ \\
\hline \multicolumn{6}{|l|}{2007} \\
\hline & 6 & Community-service doctors & & $x$ & $x$ \\
\hline & 8 & $\begin{array}{l}5^{\text {th }} / 6^{\text {th }} \text {-year medical students } \\
\text { (Student intern complex) }\end{array}$ & $x$ & $x$ & \\
\hline \multicolumn{6}{|l|}{2008} \\
\hline & 2 & $\begin{array}{l}5^{\text {th }} / 6^{\text {th }} \text {-year medical students } \\
\text { (Student intern complex) }\end{array}$ & $x$ & $x$ & \\
\hline & 1 & Canadian doctor & & $x$ & $x$ \\
\hline & 3 & Medical officers & & $x$ & $x$ \\
\hline \multicolumn{6}{|l|}{2009} \\
\hline & 1 & Registrar & & $x$ & $x$ \\
\hline & 3 & $\begin{array}{l}5^{\text {th }} / 6^{\text {th }} \text {-year medical students } \\
\text { (Student intern complex) }\end{array}$ & $x$ & $x$ & \\
\hline & 5 & Medical officers & & $x$ & $x$ \\
\hline & 12 & Clinical associate students & $x$ & & \\
\hline & 1 & Registered nurse & $x$ & & \\
\hline & 3 & Family physicians & & $x$ & $x$ \\
\hline \multicolumn{6}{|l|}{2010} \\
\hline & 15 & Medical doctors ( ${ }^{\mathrm{a} A R V}$ clinics) & $x$ & $x$ & $x$ \\
\hline & 1 & Community-service doctor & $x$ & $x$ & $x$ \\
\hline
\end{tabular}

Table I shows, at different stages of their medical education and career, 62 healthcare professionals observed, assisted or performed circumcisions and related penile surgeries under professional supervision.

\section{Circumcision scheduling and the establishment of circumcision weeks}

The approach to circumcision surgical skill training was refined over the three-year period, both to expand and to intensify the learning and service-provision opportunities.

In 2007, prospective patients who presented themselves at the hospital requesting circumcision received operations on a booking basis, as and when they could be scheduled. In 2008, the family physician scheduled patient requests for circumcision once or twice a month based on theatre availability. In the winter of 2008 , as a result of media reports that over 50 septic circumcisions had been admitted to one hospital in the region, it was decided to offer safe medical circumcisions to boys and men before the period when traditional initiation schools are generally held: the so- called circumcision season. In 2009 and 2010, patients requesting circumcisions were scheduled for procedures under local anaesthetic during circumcision weeks (May and February, respectively). In 2010, the week included a day of theoretical education for trainees which was led by a family physician and a sociologist, which included HIV education, followed by four days of intensive training through supervised practical application.

\section{Discussion}

From a traditional and cultural, as well as a biomedical, perspective, there is clear evidence of interest in, and a need for, male circumcision surgery as a procedure that is readily available in the South African healthcare system. This was the case, even prior to recent discussions on the incorporation of circumcision into the country's national HIV-prevention strategy. By 2009, the demand for medically safe circumcisions performed at this one site more than doubled (from 38-88), with an additional 31 circumcisions carried out by February 2010 , the end of the review period.

The data show that it is possible to provide this service safely and effectively at a district level in the state healthcare system. In general, teen and adult male circumcision can be performed under local anaesthetic. General anaesthesia is only necessary for pre-teen patients, or where patient anxiety or fear is particularly high. Circumcision weeks make it possible to increase the scale of service delivery to meet the growing demand.

This review suggests that there are service, education and training advantages to be gained from concentrating circumcision surgery into circumcision weeks.

In service-delivery terms, staging circumcision weeks prior to circumcision season created opportunities for teens and young adult males to be safely circumcised, before embarking on their traditional rite of passage into manhood. In the South African context, it was a proactive intervention designed to prevent adverse events that arise from non-medical circumcisions. Circumcision weeks also contributed to a growth in community interest in having the procedure carried out medically. In 2010, the demand for circumcisions was sufficient to stage a second week at the study hospital in May 2010.

In education and training terms, circumcision weeks increased opportunities for learning and practice for medical and allied healthcare students, and also for newly qualified and established doctors. The value of these weeks is that they integrated academic education with practical training in a concentrated period. During the February 
2010 circumcision week, the first day was set aside for formal lectures, followed by observation, assistance and independent surgery on the remaining days.

This meant that participant doctors were first instructed in male circumcision surgery theory, following which they then observed one or two procedures, assisted in a few, and independently performed some more under the guidance of the family physician. The February 2010 intervention was specifically run to upgrade the surgical skills of doctors working in antiretroviral clinics, and during this time, two complications relating to bleeding arose from a lack of basic training in surgical skills, an area of competency that, until now, has not been particularly important to clinicians who specialise in HIV/AIDS treatment. Circumcision weeks also made it possible to increase the scale of training.

\section{Conclusion}

Medical circumcision surgery is a safe procedure that impacts insignificantly on patient time and functional recovery, while meeting traditional and cultural, as well as individual and public health needs. It can be effectively delivered to teens and adult men under local, and where necessary, general anaesthetic. In order to make the service widely available, it is necessary to proactively educate and extensively train medical students and clinicians in circumcision surgery.

One approach to meeting the growing public demand for circumcision and to upscaling the attendant clinician skill levels is to hold circumcision weeks under the supervision of family physicians at Level 1 district hospitals across the country.

\section{References}

1. Ben Chain J, Livne PM, Binyamini J, et al. Complications of circumcision in Israel: a one year multicentre survey. Isr Med Assoc J. 2005;7(6):368-370.

2. Peters FM. Basic surgical skills training required by junior doctors to ensure competency as GPs. Conference presentation/poster. SAAHE abstracts, Cape Town, 2009.

3. Meissner O, Buso DI. Traditional male circumcision in the Eastern Cape: scourge or blessing? S Afr Med J. 2007;97(5):371-373.

4. The application of health standards in Traditional Circumcision Act of 2001.

5. Peltzer K, Nqeketo A, Petros G, Kanta X. Traditional circumcision during manhood initiation rituals in the Eastern Cape, South Africa: a pre-post intervention evaluation. BMC Public Health. 2008;19(8):64.

6. Peltzer K, Kanta X. Medical circumcision and manhood rituals in the Eastern Cape, South Africa: a post intervention evaluation. Cult Health Sex. 2009;11(1):83-97.

7. Bongaarts $\mathrm{J}$, Reining $\mathrm{P}$, Way $\mathrm{P}$, et al. The relationship between male circumcision and HIV infection in African populations. AIDS.1989;3:373-377.

8. Siegfried N, Muller M, Dewks JJ, Volmink J. Male circumcision for the prevention of heterosexual acquisition of HIV in men. [Cochrane Review]. In: The Cochrane Library, Issue 2, 2009. Oxford: Update Software.

9. Alsallaq RA, Cash B, Weiss HA, et al. Quantitative assessment of the role of male circumcision in HIV epidemiology at the population level. Epidemics. 2009;1:139-152.

10. Morris BJ. Male circumcision guide for doctors, parents, adults and teens [homepage on the Internet]. c2010. Available from: www.circinfo.net

11. Tobian AR, Serwadda D, Quinn TC, et al. Male circumcision for the prevention of HSV-2 and HPV infections and syphilis. N Engl $\mathrm{J}$ Med. 2009;360(13):1298-1309.

12. Auvert B, Sobngwi-Tambekou J, Cutler E, et al. Effect of male circumcision on the prevalence of high risk human papilloma virus in young men: results of a randomised controlled trial conducted at Orange Farm, South Africa. $J$ Infect Dis. 2009;10:14-29.

13. Castellsague X, Bosch FX, Munoz N, et al. Male circumcision, penile human papillomavirus infection and cervical cancer in female partners. N Engl J Med. 2002;346:1105-1112.

14. Bailey RC, Moses S, Parker CB, et al. Male circumcision for HIV prevention in young men in Kisumu, Kenya: a randomized control trial. Lancet. 2007;369:643-656.

15. Gray RH, Kigozi G, Serwadda D, et al. Male circumcision for HIV prevention in men in Rakai, Uganda: a randomized trial. Lancet. 2007;369:657-666.

16. Bleeker MCG, Heideman DAM, Snijders PJF, et al. Penile cancer: epidemiology, pathogensis and prevention. Word J Urol. 2009;27:141-150.

17. Personal communication from Waskett $\mathrm{JH}$ to Morris $\mathrm{BJ}$, reported in Morris $\mathrm{BJ}$. Male circumcision guide for doctors, parents, adults and teens [homepage on the Internet]. Available from: www.circinfo.net

18. Ewings $P$, Bowie C. A case-control study of cancer of the prostate in Somerset and east Devon. Br J Cancer. 1996;74:661-666.

19. Richter L, Sithole B, Mbehele L, et al. Only skin deep: limitations of public health understanding of male circumcision in South Africa. S Afr Med J. 2009;99:647.

20. Letsie TKM. Cultural male circumcision and its acceptability. Lesotho Medical Association Journal. 2007;5(2):16-19.

21. Bateman C. Millions of snips will bolster our health system. S Afr Med J. 2009;99(12):840-844 